\section{Silêncios e segredos: aspectos (não falados) da conjugalidade face à sorodiscordância para o HIV/AIDS}

\author{
Secrets and silences: unspoken aspects of conjugal \\ life for HIV/AIDS serodiscordant couples
}

\author{
1 Instituto de Saúde da \\ Comunidade, Universidade \\ Federal Fluminense, Niterói, \\ Brasil. \\ Correspondência \\ I. Maksud \\ Instituto de Saúde da \\ Comunidade, Universidade \\ Federal Fluminense. \\ Rua Marquês do Paraná 303, \\ 30 andar, Niterói, $R J$ \\ 24033-900, Brasil. \\ iviamaksud@id.uff.br
}

\begin{abstract}
One of the current issues raised by HIVIAIDS is the phenomenon of serodiscordance: affectivesexual relations between partners with different HIV serology. The article analyzes issues that cannot be discussed within established relationships in these couples and/or with family, friends, and neighborhood networks. The article discusses two dimensions of silences and secrets in serodiscordant relationships: (1) individual secrets and silences that are established for each member of the couple and (2) double secrets, established by the couple in relation to others. The article is based on in-depth interviews with 26 serodiscordant couples. The analysis was based on comparative systematization, which allowed observing how the same thematic contents varied according to the interviewee's gender and HIV status. The data show how the subjects develop daily strategies to maintain aspects of private life that can be threatened by the dynamics of gossip, understood not as an independent phenomenon, but as a function of collective norms and beliefs in given social spaces.
\end{abstract}

HIV Seropositivity; Marriage; Sexuality
Ivia Maksud 1

\begin{abstract}
"Hoje, seria necessário em termos ideais, entre os parceiros, não esconder nada, dizer tudo, revelar suas infidelidades, confessar até suas masturbações" 1 (p. 189).
\end{abstract}

\section{Introdução}

As últimas três décadas acumularam muitas investigações de caráter sociológico sobre a epidemia de HIV/AIDS. Muitos temas estiveram em pauta, na maioria das vezes acompanhando as dinâmicas sociais que se colocam a partir das tendências epidemiológicas. Parte expressiva da produção bibliográfica sobre HIV/AIDS voltouse para a sexualidade, de certa forma inaugurando e fortalecendo o que viria a se configurar como um fértil campo de estudos para as Ciências Sociais 2. A partir da década de 80 , realizam-se, no Brasil e no mundo, muitas pesquisas sobre homossexualidade $3,4,5,6$, podendo também ser encontradas, ainda que em menor número, pesquisas sobre os usuários de drogas injetáveis 7 . Na década de 90, acompanhando tanto a "feminização" da epidemia de HIV/AIDS quanto o fortalecimento do campo dos estudos de gênero no Brasil, também pode ser levantada vasta bibliografia sobre mulheres e AIDS. Parte desses estudos destinou-se às questões de saúde sexual e reprodutiva 8,9,10. A partir dos anos 2000, estudos sobre crianças e adolescentes soropositivos foram impulsionados 11,12,13. 
Uma das "novas" situações, que acompanham também as tendências epidemiológicas e como as pessoas respondem a essas, é o fenômeno da sorodiscordância: relações afetivo-sexuais entre parceiros com sorologias distintas para o HIV/AIDS. O termo, ao lado de outros como sorodivergência e sorodiferença, consta, desde meados da década de 1990, de artigos médicos norte-americanos e franceses. Segundo Remien et al. 14 e Remien 15, essa modalidade de relacionamento passa a ser cada vez mais frequente pela melhoria da qualidade e expectativa de vida das pessoas soropositivas.

No plano das Ciências Sociais em interface com a Saúde, referências sobre a temática são recentes e, quando olhadas em conjunto, ainda que reflitam distintas inspirações teóricas, têm a característica de terem sido impulsionadas por pesquisadores de alguma forma ligados (em quadros profissionais ou de colaboração) a ONG/ AIDS. Essas pesquisas mostram que a sorodiscordância não é necessariamente um novo tema, mas que adquire sentido justamente com a melhoria da assistência 16,17,18,19,20,21. No entanto, os casais sorodiscordantes suscitam outros desafios em termos de resposta à Saúde Pública, como a ampliação do referencial de prevenção (que deve pensar também os cuidados para os soropositivos), a garantia de assistência pelos serviços de saúde em caso de "acidente sexual", bem como a perspectiva da assistência integral aos direitos reprodutivos 22,23,24,25,26.

Este artigo se restringirá à discussão de "temas que não podem ser falados" no interior de relações constituídas entre casais e/ou desses com familiares, amigos e redes de vizinhança acerca do tema do HIV/AIDS. A despeito da ordem que preconiza os relacionamentos conjugais modernos, conforme se depreende da epígrafe que inaugura o artigo, podem ser muitos e de várias ordens os "silêncios" e os "segredos" contidos nas relações sociais estabelecidas entre afins. No texto, são discutidas duas dimensões dos silêncios e segredos contidos em relações sorodiscordantes: (1) segredos individuais que estabelecem silêncios para cada membro da díade, e (2) segredos de casal, estabelecidos e guardados pelo par frente a outras pessoas.

\section{Metodologia}

$\mathrm{O}$ artigo deriva de pesquisa com casais sorodiscordantes para o HIV/AIDS em que foram realizadas 26 entrevistas em profundidade com homens e mulheres de 13 casais heterossexuais sorodiscordantes 18,22 .
Dada a dificuldade de localizar pessoas que estivessem em relacionamentos desse tipo, algumas estratégias foram utilizadas para acessar possíveis entrevistados: (1) veiculação da pesquisa em revistas da área de saúde; (2) divulgação da investigação entre profissionais de saúde; e (3) solicitação de acesso a pacientes de um serviço de referência para HIV/AIDS. Essas vias resultaram em dois conjuntos de entrevistas.

O primeiro conjunto de entrevistas caracterizou-se por quatro casais residentes em diferentes estados, sendo a maioria das entrevistas realizadas em suas próprias casas 27 . O segundo bloco de entrevistas resultou em 18 entrevistas feitas em um serviço de saúde na cidade do Rio de Janeiro, sendo metade dos pacientes do serviço e a outra metade seus parceiros. Os casais entrevistados foram selecionados e consultados para participar da pesquisa por profissionais de saúde do serviço. As entrevistas foram realizadas pela pesquisadora no próprio serviço de saúde. Não houve intenção de avaliar o serviço e tampouco contrastar os dois conjuntos de entrevista.

Todas as entrevistas foram admitidas por meio de consentimento livre e informado. Foram utilizados dois roteiros distintos com núcleos temáticos comuns, um deles destinado aos soropositivos e o outro aos soronegativos. Os membros dos casais não foram entrevistados simultaneamente para minimizar o bias e a interferência de um informante sobre o outro. Todos os entrevistados aquiesceram que cada um do casal faria uma entrevista individual. Essa estratégia de abordagem permitiu enxergar distintas formas de percepção e significação dos fatos segundo o gênero do entrevistado e sua sorologia para o HIV/AIDS, positiva ou negativa.

A análise foi realizada a partir de um quadro de sistematização comparada, que permitiu observar como os mesmos conteúdos temáticos variavam de acordo com o gênero e a sorologia dos entrevistados. Adotou-se, como principal referência para a construção da análise, o trabalho de Becker 28,29, autor que propõe uma metodologia mais artesanal de fazer ciência, na qual o pesquisador pode produzir o método adequado para realizar seu trabalho e resolver seus problemas. Observações registradas no caderno de campo, especialmente o não dito, as pausas e os olhares, também subsidiaram a análise. Observaram-se diferenças nas respostas às entrevistas e, mais ainda, de posturas e reações de homens e mulheres no contexto da abordagem.

Cabe registrar que, na medida em que o objeto sociológico enfoca sujeitos humanos 30 e, nesse caso, a experiência de uma doença que ainda não tem cura, os sentimentos provocados fazem do exercício de relativização uma tarefa 
complexa. O fato de alguns entrevistados não terem se indagado sobre algumas questões surgidas durante a pesquisa impedia o aprofundamento de perguntas delicadas, como as relativas ao medo de transmissão e à separação motivada pelo HIV/AIDS. Como questiona Becker 29 (p. 53), "até que ponto a declaração do informante seria a mesma na ausência do observador, seja ela feita espontaneamente ou em resposta a uma pergunta?". Por fim, lembra-nos Bourdieu 31 que é o pesquisador que inicia e estabelece a regra do jogo e atribui à entrevista, unilateralmente $\mathrm{e}$ sem negociação prévia, os objetivos - às vezes confusos para os entrevistados - presentes numa relação dissimétrica.

Houve devolutiva dos principais resultados da pesquisa em congressos científicos e em organizações e fóruns políticos que discutem a temática do HIV/AIDS no Brasil.

\section{Resultados e discussão}

As Ciências Sociais têm possibilitado à Saúde Coletiva aprofundar a reflexão sobre temas por vezes naturalizados na área da saúde. Este artigo considerou, por exemplo, o processo de construção dos sujeitos a partir de suas biografias, bem como a relevância dos parceiros na socialização, ou seja, na construção (por vezes inconscientemente) compartilhada de crenças, sentimentos e comportamentos $32,33,34$.

Os entrevistados evidenciam perfis diferenciados. Em relação ao primeiro conjunto de entrevistas (casais 1 a 4), observa-se que os informantes não compunham um grupo social no sentido estrito, pois não pertenciam a uma mesma região geográfico-social e não havia semelhança em suas trajetórias de vida. Dois casais moram em São Paulo (capital). Duas mulheres e um homem podem ser classificados como profissionais liberais, com formação superior, e o outro homem é comerciante. Os dois casais moram em casas separadas, e todos definem seu vínculo como "namoro". Nos outros dois casais, os pares consideram-se "casados" e residem juntos na região central e na zona norte do Rio de Janeiro, sendo um deles formado por profissional autônomo e cabeleira, e o outro, por comerciante e auxiliar de enfermagem. Nesse primeiro conjunto de entrevistas, os casais estavam formados há, no máximo, cinco anos.

O perfil dos entrevistados do segundo grupo (casais 5 a 13) revela renda familiar até três salários mínimos e moradia em zonas populares do Estado do Rio de Janeiro. Em três dos nove casais, as mulheres não exerciam qualquer atividade profissional e não possuíam renda. As ocupações eram majoritariamente de empregados dos setores de serviço e trabalhadores excluídos do mercado formal. A escolaridade variava do Ensino Fundamental ao Médio, e, em sete de nove casais, os homens tinham mais anos de estudo. Havia também a tendência de o homem ser mais velho que sua companheira. A maioria dos entrevistados pertencia ou havia pertencido à religião evangélica. Nesse conjunto de entrevistas, a maioria dos entrevistados residia com seu parceiro - e alguns também com outros familiares -, o tipo de vínculo foi descrito de várias formas (companheiro, marido, esposa, casamento, ficante), e o tempo de vínculo variou de um a 38 anos.

A análise contrastiva das entrevistas evidencia que certos eventos relatados por um dos parceiros não são necessariamente conhecidos pelo outro. Simmel 35, em estudo sobre o segredo, argumenta que tudo o que se comunica a outros, inclusive aquilo que pode parecer mais subjetivo, espontâneo e confidencial, é uma seleção do real. O que é revelado, sobretudo aos mais íntimos, são fragmentos da vida real interior. Nesse sentido, toda mentira - entendida pelo autor como "a limitação do conhecimento que um tem do outro" 35 (p. 365) - seja qual for sua natureza, produz um erro acerca do sujeito que mente: o mentiroso esconde de seu interlocutor a sua verdadeira representação. Para o autor, as resoluções são construídas sobre um complexo sistema de representações, a maioria das quais supõe a confiança. Por essa razão, a mentira é muito nociva na vida moderna. Paradoxalmente, é um elemento central na estrutura das relações.

\section{Segredos individuais}

Um contexto que configura tensões e silêncios conjugais, para a maioria dos casais, diz respeito ao recebimento da notícia da soropositividade de um dos parceiros. A análise de entrevistas masculinas mostra que, para alguns entrevistados soronegativos, certas "habilidades" foram significativas para a continuidade do relacionamento após a revelação do status positivo da parceira. Referiram-se a eventos de vida associados ao ato de cuidar (parentes doentes na família, por exemplo) e que é preciso habilitar-se, o que requer um processo entendido como uma fase de "amadurecimento", “aprendizagem" e "solidariedade". Um dos entrevistados havia tido anteriormente outra namorada soropositiva: "na primeira vez, teve um susto, e então agora estava amadurecido”. Outro entrevistado acompanhou o adoecimento e falecimento de um familiar e não achava justo abandonar sua namorada quando ambos passavam por um período de declarado sofrimento. 
"Entrou de cara e de peito" e acha que foi mais uma "provação" dada a ele por uma "força divina”: "eu vou dar a ele porque ele é forte, já teve outros tombos, vai aguentar esse rojão”. Um terceiro entrevistado havia tido uma experiência pessoal com outra doença, que fez com que ele percebesse o HIV "como fichinha".

No entanto, a experiência anterior que habilita não elimina uma série de sentimentos referidos como "responsabilidade", "compaixão" e "receio de magoar os parceiros soropositivos", temas tabus 36 que não podem, segundo os soronegativos, ser conversados abertamente na relação.

Em algumas entrevistas com homens, a "responsabilidade” foi mencionada com parcimônia, assumindo ares de desabafo ao longo da narrativa. A proteção às mulheres, o receio de magoálas e a avaliação de que precisam de cuidados permanentes são representações elaboradas pelos homens. A proteção ofertada às mulheres, em certa medida, apresenta-se tanto como responsabilidade moral de manutenção material como no sentido de companhia, excetuando-se a participação masculina na esfera doméstica. Quanto ao acompanhamento na rotina de exames e consultas, há menor participação dos homens em relação às mulheres, em contraste à situação em que são os homens soropositivos e as mulheres negativas.

A descoberta da soropositividade do parceiro apresentou-se de forma diferenciada para as mulheres soronegativas. Uma delas considerava que seu marido poderia ser usuário de drogas e bissexual, mas não queria abordar o assunto e lhe sugeriu, em uma ocasião, que fizesse o teste. Afirmava que o amava e queria estar casada com ele. Embora considerasse que o sexo não é o mais importante num relacionamento, tinha vontade de ter relações sexuais - e, algumas vezes, eventualmente, sem preservativo. Em seu discurso, relatou que, se um dia adquirisse o vírus, poderia conviver bem com essa situação. Outra mulher fez o teste com seu marido em consequência do adoecimento de sua ex-mulher e relatou ter "ficado triste por ele, mas feliz por ela". A partir daquele momento, "tornara-se mais humana: era então o momento de apoiá-lo”. Em um outro casal, esse de muitos anos, a mulher desconfiava das relações extraconjugais do marido com outras mulheres. Sem escolaridade, essa mulher - evangélica - nunca trabalhou, e esse homem foi seu único parceiro sexual. Relata, por um lado, ajudá-lo com os medicamentos e alimentação, e, por outro, discorre sobre a violência doméstica sentida ao longo dos anos. Esse complexo quadro resulta em separação de copos e talheres, manutenção de relações sexuais duas a três vezes por semana sem beijos na boca (como ele tem hepa- tite, “não gosta de beijo meloso") e ocultamento da condição soropositiva do parceiro (apenas os filhos sabem). Outra mulher relatou sentimento de raiva com a descoberta da soropositividade do seu companheiro ("a gente não tá vivendo bem”), associando-a a possíveis traições ("ele sempre foi muito mulherengo"), contudo, afirmava seu desejo de permanecer com ele.

Um dado recorrente nas entrevistas diz respeito à indefinição, ao constrangimento ou ao segredo em relação à origem da transmissão. Esse é um tema sobre o qual muitos entrevistados referem dúvidas e relatam não saber, ao certo, como se infectaram. O que pode e deve ser lembrado e explicitado como tema entre o casal é um exercício realizado estrategicamente pelos parceiros, ainda que, muitas vezes, esse processo se apresente de forma aparentemente espontânea.

Alguns entrevistados, homens e mulheres, revelaram ter conhecimento sobre como se infectaram, mas decidiram não revelar essa informação aos parceiros. Soropositivos afirmam não querer fornecer detalhes ao parceiro por vergonha e receio e tendem a considerar que as experiências pessoais do passado deporiam contra uma imagem social ideal. Por outro lado, alguns soronegativos referiram, nas entrevistas, curiosidade e desinformação sobre a infecção de seus parceiros. De fato, o "passado", como aponta a literatura antropológica 37 , passa a ser relido conjuntamente pelo par, denotando e construindo uma zona única, comum aos dois parceiros. $\mathrm{E}$ quando detalhes do passado são subtraídos, configura-se também uma área de tensão, com possíveis acusações entre os parceiros. Os relatos abaixo, provenientes de dois casais distintos, elucidam como insinuações podem ser geradas no âmbito do par devido à curiosidade sobre a origem da transmissão: "Ela chegou a falar que era impossível eu não saber com quem peguei. Chegou a falar que eu devia ter transado com algum homem e tal. Mas eu falo que não sei e ela acha que sei" (homem soropositivo). "Ele não sabe como pegou. Ou se sabe não quer contar" (mulher soronegativa).

Alguns entrevistados soronegativos relataram a revelação da soropositividade do parceiro para o melhor amigo ou para alguém de muita confiança. Nesse caso, essa informação é ocultada no âmbito do casal, havendo desconfiança do parceiro soropositivo acerca de quem sabe ou não sobre sua doença. Em geral, a suspeição de falar sobre o tema recai sobre as mulheres: "Contei para uma amiga. Ele não sabe que ela sabe. Ele não quer que ninguém saiba" (mulher soronegativa). "Acredito que mais gente deva saber, porque ela fala muito” (homem soropositivo). 
Há apenas um relato masculino em que se explicita a revelação da soropositividade da parceira à família. Trata-se, nesse caso, de um casal jovem, em que o rapaz avisou à moça soropositiva que contaria e preparou seus pais para o recebimento da notícia. Essa preparação significou traduzir para os pais o sofrimento vivenciado pela jovem mulher.

Um dos homens soronegativos diz que ninguém em sua família sabe da soropositividade de sua esposa. No entanto, desconfia que sua mãe saiba "porque sua ex-mulher poderia ter contado", pois "usa esta informação como arma". Ele relata que "não tem hábito de falar" sobre o assunto.

Ao lado de uma maior discrição masculina sobre o tema, figura um discurso do direito à fala ("o direito de falar é dela" - que é soropositiva, revela um homem soronegativo), e, ainda, está em jogo uma preocupação com os prejuízos sociais que essa condição acarretaria. O mesmo entrevistado, soronegativo, complementa: "Minha família ficaria apavorada!".

Nas experiências amorosas cotidianas tradicionais, fundadas no ideário de amor romântico ou na ideia de amor-paixão e baseadas na atração física, a contabilidade sexual está no centro da construção diária do sentimento percebido como amor 1,37,38. O sociólogo francês Michel Bozon 38 demonstra que há uma diminuição da atividade sexual entre aqueles que chama casais estabilizados. No entanto, observa, ao lado de autores como Béjin 1, a obrigatoriedade do sexo nos casamentos contemporâneos como uma espécie de termômetro e mantenedor dos vínculos afetivo-sexuais. Para os casais sorodiscordantes, a essas concepções de amor agregamse sentimentos descritos como cuidado, apoio, solidariedade e responsabilidade. A manutenção do vínculo pode colocar em questão a gestão do risco de transmissão do HIV entre os casais. O discurso feminino recorrentemente faz menções ao medo da transmissão (seja "passar o HIV" ou “pegar o HIV”) 22.

Outro tema sobre o qual se constitui segredo é o exercício da extraconjugalidade, prática considerada inadequada em um relacionamento conjugal pela maioria dos entrevistados. A naturalização da ideia de relação sexual exclusiva com o/a cônjuge ou com quem se mantém uma relação concebida como estável pressupõe a ideia de fidelidade. Essa concepção ideológica, entretanto, nem sempre se sustenta na prática, representando mais um tema sobre o qual não se fala, sob pena de arruinar o vínculo conjugal.

Nenhuma mulher referiu manter ou ter tido relacionamentos extraconjugais paralelos com outros homens ou mulheres. O contrário foi mais comum nos relatos de homens que disseram manter ou ter mantido relações extraconjugais sem que isso signifique, para eles, ameaça à dissolução da relação. Apenas dois homens relataram relações sexuais com outros homens. Nos dois episódios, o exercício sexual com parceiros do mesmo sexo não fora considerado como identidade bissexual ou homossexual. Em um dos casos, o envolvimento sexual com homens se deu em uma fase inicial da juventude; no outro, continuava a ser exercido concomitantemente ao relacionamento estável com sua parceira. Quando comparadas à relação conjugal, as relações extraconjugais com outros homens perdem relevância frente a outros valores presentes no par, não necessariamente alocados na obtenção de prazer sexual. Além disso, os relatos indicam que o sexo ocupa ou passa a ocupar posição subordinada frente a outros sentimentos como o amor, o cuidado ou a companhia. Nesse caso, o segredo oferece a possibilidade de emergência de um segundo mundo, que passa a existir ao lado do mundo oficial 35,39. Como mostrou Béjin 1, a relação extraconjugal é buscada pelas alegrias e satisfações sexuais que ela poderia proporcionar, podendo transgredir mais facilmente as barreiras sexuais. Porém, permanece como relação não oficial e, portanto, invisível na ordem social.

A experiência da doença, além de modificar o curso da vida e a própria representação sobre a doença, modifica a relação dos sujeitos com o tempo. Apesar de não haver uma preocupação explícita com a morte iminente, o discurso dos entrevistados evidenciou a "necessidade de aproveitar a vida" e "viver bem o presente". Como afirma uma mulher soropositiva: "Não faço planos devido ao HIV. Deixo as coisas acontecerem. $O$ sonho era ter uma casa, cheia de amigos e filhos. Mas o mal tomou conta".

Há uma preocupação com o futuro dos dependentes, que se coloca ao lado de uma certa perspectiva acumulativa: a importância de guardar recursos para garantir a vida dos filhos ou fazer planos de adquirir casa própria. Para além do cuidado com "os outros", a doença contribui para uma percepção e importância de si, e figuram nos discursos os verbos "viajar", "aproveitar" (a vida) e "investir" (na carreira profissional). Há uma revisão das prioridades de vida, aliando planejamento a destino: deixar as coisas acontecerem no seu tempo. Os soropositivos consideram que têm um tempo limitado de vida, identificado como diferente do tempo que dispõe o parceiro soronegativo. Algumas crenças religiosas corroboram essas representações, expressas por frases como: "viverei o tempo que Deus achar que devo viver”. 


\section{Segredo de casal e fortalecimento do par}

Os dados da pesquisa apontam para algumas relações estabelecidas entre o casal sorodiscordante com suas famílias e outras redes sociais, chamadas aqui de "segredos conjugais". Esses se constroem, na tentativa de evitar as fofocas e a desvalorização da honra dos parceiros a partir da doença, como segredos que reforçam a coesão da relação conjugal frente a outras relações sociais.

O termo "fofoca" é aqui utilizado de acordo com a classificação nativa e aproxima-se da definição contida na obra de Elias 40 . Para esse autor, fofocas são "as informações mais ou menos depreciativas sobre terceiros, transmitidas por duas ou mais pessoas umas às outras" 40 (p. 121). É dessa forma que a AIDS torna-se um segredo conjugal. Apesar de a família ser uma instituição central para os entrevistados, a existência de um segredo comum acaba por autonomizar o casal frente a essa agência. O sigilo da doença é concentrado no casal, justamente para mantê-lo. Não é uma tarefa fácil, uma vez que muitos pares - sobretudo aqueles do segundo conjunto de entrevistas - compartilham o mesmo quintal que seus familiares, o que reduz a privacidade para assuntos de casal. Como mostrou Fonseca 41 (p. 63), "a unidade residencial é uma categoria-chave para análise das relações sociais estabelecidas no universo".

Em geral, os entrevistados administram, em algum grau, o desafio de esconder a própria soropositividade ou a de seu parceiro. Para uma das mulheres, apenas os profissionais de saúde que a atendem e o seu parceiro sabem de sua condição. Somente uma outra entrevistada, que refere ser ativista do movimento social de luta contra a AIDS, escapa a essa lógica e publiciza sua doença. No entanto, mesmo essa mulher referiu " $n e$ cessidade de um tempo para acostumar-se" com a sua condição para, posteriormente, contar a alguns membros da família e, por fim, torná-la pública.

A decisão sobre "contar ou não" é construída entre os sentimentos de escolha e obrigação. $\mathrm{O}$ tema é considerado digno de ser revelado a alguém em quem se confia, e seu ocultamento pode provocar a ruptura da lealdade. Poucas pessoas são escolhidas para a revelação: o segredo é facultado a alguns familiares que possam apoiar os soropositivos em momentos difíceis. Além de alguns membros da família, "amigos como se fossem irmãos" também são guardiões do segredo. Os membros da família eleitos para guardar o segredo, no entanto, contam a notícia para outros familiares. Alguns entrevistados dizem suspeitar que outros familiares saibam do fato. Dessa forma, a notícia pode se espalhar nas redes sociais sem que seja possível um controle da informação. Essa situação tende a ser mais acentuada quando se trata da relação entre familiares e redes de vizinhança. Em vários relatos, foi referida uma estratégia de "não confirmação" da notícia em que as personagens principais deixam em dúvida os demais atores sociais.

"No caso dele, muita gente ficou sabendo por causa da sua ex-esposa. Família... amigos... vizinhos... Os comentários existem... Todo mundo viu o filme Cazuza. Mas ele nunca confirmou nada e deixa as pessoas em dúvida. Na família dele todo mundo sabe... Ninguém ali guarda segredo. Na minha família, meus irmãos sabem. Um irmão contou para uma irmã, que contou para minha mãe" (mulher soronegativa).

A ideia de "preparar" aqueles que receberão a notícia se apresenta ao lado da preocupação com a imagem e a moral do sujeito soropositivo e permeia o processo até que se chegue ao momento da revelação e às formas e/ou estratégias para contar. Pode-se articular essa ideia ao que Goffman 42 denomina como "representação do eu". O autor aproxima o ator social ao ator de teatro, mostrando a habilidade das personagens sociais para escolher o palco, a peça e o figurino a serem utilizados de acordo com cada público, visto que seu principal objetivo é manter sua coerência e se ajustar a cada situação a partir da interação com outros atores.

Uma das entrevistadas contou sua sorologia positiva para sua mãe em um momento de raiva e emoção, num contexto de desentendimento familiar, três anos após a descoberta. Pediu que ela não falasse para ninguém, mas essa revelou aos outros filhos: "não para fofocar, mas para dividir a angústia", para que "eles a protegessem". A mesma entrevistada preparou-se por mais tempo para contar à sua filha: "Eu programei. Tinha que programar isso dentro de minha cabeça, eu não poderia falar isso de qualquer jeito".

Nessa preparação, é central a valorização da experiência do sofrimento da pessoa soropositiva. O depoimento de um entrevistado soronegativo ilustra a forma de revelar o segredo de sua esposa, soropositiva: "Preparei meus pais para contar. Disse a eles o quanto ela tinha sofrido".

Alguns casais revelam a condição para poucos familiares, que ocultam a informação de outros membros do grupo. Um dos casais contou apenas para os filhos sobre a doença do homem. Nenhum outro familiar sabe do fato - nem os genros - porque o casal receia que os familiares deixem de frequentar sua casa e teme ser alvo de fofocas.

Mas nem sempre os filhos sabem sobre a doença de um dos pais. Quando são considerados muito jovens não lhes é contado o segredo, e há 
quem pense que a revelação, quando feita, deverá servir para educá-los, mostrando o caso como resultado de uma conduta errada: "Fico pensando no filho crescendo... se devo falar ou não. Um dia terei que falar: teu pai ficou assim porque fez coisa errada" (mulher soronegativa).

Em três casais, havia outras pessoas soropositivas na família, o que tampouco é garantia de revelação espontânea. Para dois casais, no entanto, a situação anterior serviu para "facilitar" a revelação, "diminuindo o impacto da notícia na família”. Num deles, a família do homem não sabe da doença de sua mulher: "eles desconfiam que ela também seja soropositiva”, o que não é desmentido pelo homem.

A revelação da sorodiscordância de um casal para as duas famílias em jogo é um evento englobado pelas relações de poder que permeiam o par. Por vezes, há uma negociação tácita entre o casal para decidir "quem está autorizado a contar" e "para quem" sobre a soropositividade de um dos parceiros: há quem considere deter o poder da fala aquele que tem o vírus. Por outro lado, há quem ache que o monopólio da confissão caiba ao parceiro que tem a família, mesmo que seja ele o soronegativo. $\mathrm{O}$ assunto ora é tido como individual, ora como problema de casal. Essa questão evidencia a força dos laços de parentesco e como consanguíneos e afins exercem influência sobre o par.

As mulheres soropositivas relataram receio de ter sua honra desqualificada pelas famílias dos companheiros. A palavra ignorância foi citada como principal causa de desconfiança. Muitas mulheres preocupam-se com a análise de sua reputação pelas sogras: "O que ela (sogra) vai pensar de mim, que eu vou infectar ofilho dela...". Uma das entrevistadas tornou-se objeto de comentários depreciativos da rede de vizinhança e é nomeada publicamente pela sogra de "bicha podre" e "piranhuda".

A fofoca presente nos relatos tem como principais funções sociais informar a reputação dos moradores de um local, consolidando ou prejudicando sua imagem pública e reforçando a coesão social das redes. As familiares de um homem soronegativo - mãe e irmãs (o pai ficou isento) - o pressionaram para que ele rompesse a aliança com a mulher soropositiva: "Achavam que ela deveria procurar soropositivos pra namorar. Minha mãe falou que sou maluco. De vez em quando, ela fala umas gracinhas para ela. Já xingou. Ela tem um preconceito grande, faz pressão. Diz que se eu tiver HIV ela se mata" (homem soronegativo).

Frequentemente, fala-se na vontade e na intenção de contar aos familiares e amigos, "inclusive para alertá-los para que tenham cuidado".
Mas, em geral, não se conta sobre a doença e recomenda-se ao parceiro que não revele o segredo, por receio de discriminação. O estigma é associado à "ignorância" e à "mente atrasada" das pessoas. A razão para a omissão é o receio de preconceito e fofoca: "Se a gente faz alguma coisa em casa, as pessoas não vão porque tem AIDS", comenta um homem soronegativo. Outro entrevistado soronegativo mantém o segredo "para evitar comentários, porque a pessoa é discriminada por estar com HIV", ou mesmo "para evitar perturbar os parentes".

"A AIDS é uma doença muito criticada. Quanto menos pessoas souberem, melhor. Tenho um bom envolvimento com minha família e isso poderia atrapalhar" (homem soropositivo).

Em geral, a rede mais extensa de amigos desconhece a condição soropositiva de um dos membros do casal. É comum a crença de que muitos amigos se distanciariam caso soubessem. Acredita-se que demonstrar conhecimento sobre AIDS nesses círculos pode ser perigoso e pode denunciar a condição. De forma aproximada, o ambiente profissional também pode ser ameaçado pela possibilidade da descoberta da soropositividade. "Manter o segredo é difícil", avalia uma mulher soronegativa. $\mathrm{O}$ valor conferido ao trabalho é uma das razões para manter a soropositividade em segredo: "Sou manicure. Se eu contar, não ganho meu pão”. Dois entrevistados provavelmente perderam seus empregos pela soropositividade. Um homem teve a soropositividade revelada por um colega aos patrões: "era olhado diferente" e "até os talheres com os quais comia ficavam separados". Uma das mulheres foi aposentada pela empresa após o diagnóstico positivo revelado em exame trabalhista.

\section{Considerações finais}

Neste artigo, colocou-se em discussão a esfera dos silêncios e segredos contidos em relacionamentos sorodiscordantes a partir da divisão tipificada entre segredos individuais e segredos de casal. Mostrou-se que cotidianamente os sujeitos realizam estratégias para manutenção de alguns aspectos de sua vida privada que podem ser ameaçados pela dinâmica da fofoca, entendida aqui não como um fenômeno independente, mas gerada em função das normas e crenças coletivas que estão em jogo em um determinado espaço social, como mostram Elias 40 e Fonseca 41 em seus trabalhos.

Os dados discutidos evidenciam que a união de pessoas consideradas sadias a outras tidas como doentes é um fato que provoca tensões, estigmas e preconceitos de várias ordens na coletivi- 
dade. No entanto, para além das tensões e estigmas que podem ser erigidos a partir da formação de casais que tenham outras diferenças - como outra doença como o câncer ou alguma deficiência -, o fato de que a transmissão do HIV se dá, sobretudo, por via sexual e que o sexo é parte da relação conjugal colocam, em evidência, a espe- cificidade e importância da sorodiscordância no debate sobre prevenção e assistência. Passadas três décadas, o conteúdo dos relatos revela que a AIDS ainda é considerada uma "doença do outro", como mostraram Knauth 10 e Guimarães 6 com suas pesquisas com mulheres no início da epidemia brasileira.

\section{Resumo}

Uma das situações atuais colocada pela epidemia de HIVIAIDS é o fenômeno da "sorodiscordância". Este artigo aborda temas que não podem ser falados em relações constituídas entre esses casais elou desses com familiares, amigos e redes de vizinhança. São discutidas duas dimensões dos segredos contidos em relações sorodiscordantes: (1) segredos individuais que estabelecem silêncios para cada membro da díade; e (2) segredos de casal, estabelecidos e guardados pelo par frente a outras pessoas. O artigo deriva de pesquisa com casais sorodiscordantes para o HIVIAIDS em que foram realizadas 26 entrevistas em profundidade. A análise foi realizada a partir de um quadro de sistematização comparada, que permitiu observar como os mesmos conteúdos temáticos variavam de acordo com o gênero e a sorologia dos entrevistados. Os dados mostram que cotidianamente os sujeitos realizam estratégias para manutenção de aspectos da vida privada que podem ser ameaçados pela dinâmica da fofoca, entendida não como fenômeno independente, mas em função de normas e crenças coletivas em determinados espaços sociais.

Soropositividade para HIV; Casamento; Sexualidade

\section{Agradecimentos}

Ao parecerista que muito contribuiu com sugestões para melhorar a qualidade do artigo.

\section{Referências}

1. Béjin A. O casamento extraconjugal dos dias de hoje. In: Áries P, Béjin A, organizadores. Sexualidades ocidentais. São Paulo: Editora Brasiliense; 1987. p. 183-93.

2. Loyola MA. Aids e sexualidade: o ponto de vista das ciências humanas. Rio de Janeiro: Editora Relume-Dumará; 1994.

3. Parker R. Corpos, prazeres e paixões. São Paulo: Editora Best Seller; 1991.

4. Terto Jr. V. Reinventando a vida: histórias sobre homossexualidade e AIDS no Brasil [Tese de Doutorado]. Rio de Janeiro: Universidade do Estado do Rio de Janeiro; 1997.

5. Rios LF. Corpos e prazeres nos circuitos de homossociabilidade masculina do centro do Rio de Janeiro. Ciênc Saúde Coletiva 2008; 13:465-75.

6. Guimarães CD. O homossexual visto por entendidos. Rio de Janeiro: Garamond Universitária; 2004.

7. Bastos FI. Ruína \& reconstrução: AIDS e drogas injetáveis na cena contemporânea. Rio de Janeiro: Associação Brasileira Interdisciplinar de AIDS/Instituto de Medicina Social, Universidade do Estado do Rio de Janeiro/ Editora Relume-Dumará; 1996.

8. Barbosa RM, Knauth D. Esterilização feminina, AIDS e cultura médica. Os casos de São Paulo e Porto Alegre. Brasil. Cad Saúde Pública 2003; 19 Suppl 2:S365-76. 
9. Corrêa S, Ávila MB. Direitos sexuais e reprodutivos - pauta global e percursos brasileiros. In: Berquó E, organizador. Sexo e vida - panorama da saúde reprodutiva no Brasil. Campinas: Editora da Unicamp; 2003. p. 17-78.

10. Knauth DR. Aids, reprodução e sexualidade: uma abordagem antropológica das mulheres contaminadas pelo vírus da Aids. Relatório final. Porto Alegre/São Paulo: Fundação Carlos Chagas/Fundação MacArthur; 1996.

11. Cruz EF. Infâncias, adolescências e AIDS. Educação em Revista 2007; 46:363-84.

12. Paiva V, Ayres JRCM, Segurado AC, Lacerda R, Silva NG, Silva MH, et al. A sexualidade de adolescentes vivendo com HIV: direitos e desafios para o cuidado. Ciênc Saúde Coletiva 2011; 16:4199-210.

13. Bueno RCO. Avaliando o presente e projetando o futuro: rede nacional de adolescentes e jovens vivendo com HIV/AIDS (RNAJVHA) - RJ: histórias de vida [Dissertação de Mestrado]. Rio de Janeiro: Universidade do Estado do Rio de Janeiro; 2011.

14. Remien RH, Carballo-Dieguez A, Wagner G. Intimacy and sexual risk behavior in serodiscordant male couples. AIDS Care 1995; 7:429-38.

15. Remien RR. Uma revisão dos desafios para casais sorodiscordantes e questões de Saúde Pública: implicações para intervenções. In: Maksud I, Terto Jr. V, Pimenta C, Parker R, organizadores. Conjugalidade e AIDS: a questão da sorodiscordância e os serviços de saúde. Rio de Janeiro: Associação Brasileira Interdisciplinar de AIDS; 2002. p. 21-5.

16. Hallal R, Ravasi G, Kuchenbecker R, Greco D, Simão M. O acesso universal ao tratamento antirretroviral no Brasil. Revista Tempus Actas em Saúde Coletiva 2010; 4:53-65.

17. Polejack L. Convivendo com a diferença: dinâmica relacional de casais sorodiscordantes para HIV/ AIDS [Dissertação de Mestrado]. Brasília: Universidade Nacional de Brasília; 2001.

18. Maksud I. Casais sorodiscordantes: conjugalidade, práticas sexuais e HIV/AIDS [Tese de Doutorado]. Rio de Janeiro: Universidade do Estado do Rio de Janeiro; 2007.

19. Mèndes-Leite R, Banens M. Vivre avec le VIH. Paris: Calmann-Lévy; 2006.

20. Silva AM. Entre a cama e o ambulatório: a biomedicina e a vida sexual dos casais sorodiscordantes com HIV/AIDS [Dissertação de Mestrado]. Rio de Janeiro: Universidade do Estado do Rio de Janeiro; 2007.

21. Lago ELM. Sorodiscordância e equipe profissional: estudo qualitativo da assistência em ambulatório de HIV/AIDS no Município de Niterói [Dissertação de Mestrado]. Rio de Janeiro: Pontifícia Universidade Católica do Rio de Janeiro; 2011.

22. Maksud I. O discurso da prevenção da AIDS frente às lógicas sexuais de casais sorodiscordantes: sobre normas e práticas. Physis (Rio J.) 2009; 19: 349-69.

23. Franch M, Perrusi A, Araújo F. Novas abordagens para casais sorodiferentes. João Pessoa: Editora Manufatura; 2011.
24. Hallal R, Rossi AS, organizadores. Recomendações para terapia antirretroviral em adultos infectados pelo HIV - 2008. Suplemento III: tratamento e prevenção. Brasília: Ministério da Saúde; 2010.

25. Rossi AS. Demandas e barreiras para o acesso a serviços de reprodução assistida para pessoas vivendo com HIV no Brasil: perspectivas de gestores, profissionais e usuários [Tese de Doutorado]. Campinas: Universidade Estadual de Campinas; 2010.

26. Vargas EP, Maksud I, Moas L, Britto RH. HIV/AIDS, direitos reprodutivos e tecnologias reprodutivas: mapeando diferentes perspectivas. RECIIS: Revista Eletrônica de Comunicação, Informação e Inovação em Saúde 2010; 4:3-11.

27. Ortner S, Whitehead H. Sexual meanings: the cultural constructions of gender and sexuality. London: Cambridge University Press; 1981.

28. Becker H. Métodos de pesquisa em Ciências Sociais. São Paulo: Editora Hucitec; 1997.

29. Becker H. Segredos e truques da pesquisa. Rio de Janeiro: Jorge Zahar Editor; 2007.

30. DaMatta R. Relativizando. Petrópolis: Editora Vozes; 1981.

31. Bourdieu P. A miséria do mundo. Petrópolis: Editora Vozes; 2003.

32. Geertz C. A interpretação das culturas. Rio de Janeiro: Jorge Zahar Editor; 1973.

33. Singly F. Livres juntos. O individualismo na vida comum. Lisboa: Publicações Dom Quixote; 2003.

34. Velho G. Individualismo e cultura. Notas para uma antropologia da sociedade contemporânea. Rio de Janeiro: Jorge Zahar Editor; 1987.

35. Simmel G. El secreto y la sociedad secreta. In: Simmel G, editor. Sociología. Estudios sobre las formas de socialización. Madrid: Alianza Editorial; 1986. p. 357-424.

36. Rodrigues JC. Tabu do corpo. São Paulo: Achiamé; 1983.

37. Heilborn ML. Dois é par: gênero e identidade sexual em contexto igualitário. Rio de Janeiro: Editora Garamond; 2004.

38. Bozon M. Sociologia da sexualidade. Rio de Janeiro: Fundação Getúlio Vargas; 2004.

39. Natividade M, Gomes E. Para além da família e da religião: segredo e exercício da sexualidade. Religião e Sociedade 2006; 26:41-58.

40. Elias N, Scotson J. Os estabelecidos e os outsiders. Rio de Janeiro: Jorge Zahar Editor; 2000.

41. Fonseca C. Família, fofoca e honra. São Paulo: Universidade Estadual Paulista; 2003.

42. Goffman E. Estigma: notas sobre a manipulação da identidade deteriorada. Rio de Janeiro: Editora Guanabara Koogan; 1988.

Recebido em 01/Dez/2011

Versão final reapresentada em 28/Fev/2012

Aprovado em 13/Mar/2012 